\title{
К ВОПРОСУ ОБ ОТБОРЕ ЛЕКСИКИ ПРИ ОБУЧЕНИИ ЯЗЫКУ СПЕЦИАЛЬНОСТИ (ДОВУЗОВСКИЙ ЭТАП)
}

\section{ON THE ISSUE OF VOCABULARY SELECTION IN TEACHING THE SPECIALTY LANGUAGE. (PRE-UNIVERSITY STAGE) \\ D. Rubtsova N. Rumyantseva}

Summary: The purpose of this article is to justify the role of vocabulary in teaching Russian as a foreign language for special purposes at the pre-University stage.The article discusses the problems of selecting lexical material when teaching the language of the specialty. The authors conduct a brief analysis of the materials of the propedeutic course using the material of literary studies and literature for students-philologists. consider the stages of introduction of terminological vocabulary, the role of typological text as the basic element of the development of communicative skills and abilities of students, as well as consider the ways of submitting lexical material in accordance with the stage of study and the level of proficiency of the Russian language as a foreign language. The typology of exercises presented in the article helps to consolidate the terminology vocabulary and allows the student to build an independent monologue statement. At the conclusion of the article, the authors offer some recommendations, among which the most significant are:

- Reliance on frequency common, general scientific, thematicterminology, corresponding to the subject content of the lesson and course in general, taking into account its semasiological and extralinguistic significance;

- Adherence to the principle of minimizing vocabulary, the concentration of its presentation;

- The use of typological texts representing vocabulary in its functional role.

Keywords: Russian as a foreign language, language of the specialty, terminology vocabulary, lexicon-semantic groups, typological text.

\author{
Рубиова Дина Николаевна \\ старший преподаватель, Российский университет \\ дружбы народов \\ dina.rubtsova@yandex.ru \\ Румянцева Наталия Михайловна \\ Д.п.н., профессор, Российский университет \\ дружбы народов \\ natrum1@yandex.ru
}

Аннотация: Целью данной статьи является обоснование роли лексики в обучении русскому языку как иностранному для специальных целей на довузовском этапе. В статье рассматриваются проблемы отбора лексического материала при обучения языку специальности. Авторы проводят краткий анализ материалов пропедевтического курса на материале литературоведения и литературы для студентов-филологов, рассматривают этапы введения терминологической лексики, роль типологического текста как основного элемента развития коммуникативных навыков и умений обучающихся, рассматривают способы подачи лексического материала в соответствии сэтапом обучения и уровнем владения русским языком как иностранным. Представленная в статье типология упражнений способствует закреплению терминологической лексики и позволяет учащемуся строить самостоятельное монологическое высказывание. В заключении статьи авторы предлагают некоторые рекомендации, среди которых наиболее значимыми являются:

- опора на частотную общеупотребительную, общенаучную, тематическую терминологическую лексику, соответствующую предметному содержанию урока и курса в целом с учётом её семасиологической и экстралингвистической значимости;

- соблюдение принципа минимизации лексики, концентричности ее презентации;

- использование типологических текстов, представляющих лексику в её функциональной роли.

Ключевые слова: русский язык как иностранный, язык специальности, терминологическая лексика, лексико-семантические группы, типологический текст.

ной и социально-гуманитарной деятельности, участвуя в межкультурном общении. В результате освоения дисциплины обучаемые должны знать: грамматические и лексические правила и нормы построения языка, характерные для общенаучной и профессиональной речи; базовую лексику, представляющую общенаучный стиль, а также основную терминологию в области узкой специализации; уметь распознавать и использовать грамматические конструкции в заданном контексте, выбирать адекватную форму речевого этикета, анализировать полученную информацию, понимать основное содержание текстов монологического характера в рамках изученных тем, вести беседу на иностранном языке на разговорные и профессиональные темы. 


\section{Результаты}

Авторы проводят классификацию лексико-грамматических единиц научного текста на материале пособий для филологов, рассматривают роль типологического текста, представляют некоторые рекомендации по презентации общенаучной и терминологической лексики, методике контроля усвоения лексических единиц в процессе их функционирования в речи.

\section{Обсужмение}

Существенная роль в процессе обучения слушателей иностранному языку отводится лексике. Более того, систематическое накопление и расширение словарного запаса учащихся является одной из важнейших задач при обучении иностранному языку. Значимость правильного владения лексикой многократно подчеркивалась в высказываниях психологов и методистов (Б.В. Беляев, Д. Уилкинс и др.): « Из всех основных аспектов иностранного языка, которые должны практически усваиваться учащимися в процессе обучения, наиболее важным и существенным с психологической точки зрения следует считать лексику, потому что без запаса слов, хотя бы и незначительного, владеть языком невозможно» [1]. Содержательная сторона обучения лексике предусматривает владение лексическим минимумом, обеспечивающим возможность развития речевых навыков и речевых умений. Сущностью отбора лексических единиц для учебных целей является выделение из множества слов устойчивых словосочетаний и речевых клише, входящих в состав данного курса и соответствующих этапу обучения. Именно для этих целей коллективами авторов были разработаны Лексические минимумы разных уровней: Лексический минимум общего владения русским языком как иностранным элементарного уровня владения (A1) русским языком содержит 780 слов, базового (А2)-1300, а первого сертификационного (В1) -2300 слов. $[2,3,4]$

Лексических минимумов профессиональной лексики для уровней A1 и А2, как известно, не существует, поскольку «Программа по русскому языку как иностранному. Элементарный, базовый, первый сертификационный уровни » [5] предписывает знание русского языка в рамках сфер повседневного и социально-культурного общения, однако на многих подготовительных факультетах российских вузов обучение языку специальности начинается с 8-9 недели, поэтому в этот период обучения главными принципами отбора лексических единиц являются:

- частотность и распространённость их употребления в рамках описываемого стиля и подъязыка науки;

- определение качественного и количественного состава лексических единиц, который может из- меняться в зависимости от коммуникативной потребности как отдельного урока, так и всего обучающего курса;

- тематическая необходимость употребления, в первую очередь, при отборе терминированной и терминологической лексики

В период начала обучения языку специальности (конец элементарного, начало базового уровня владения русским языком как иностранным (РКИ)) лексический запас слушателей невелик, примерно 500-550 слов, а грамматика, освоенная в процессе занятий на элементарном уровне, не выходит за рамки предложно - падежной системы существительных. В связи с этим исчисление лексических единиц, которые могут быть усвоены обучающимися в пределах времени, отведённого для изучения того или иного курса научного стиля речи, должно быть выявлено на основе научных и практических данных.

Законы восприятия лексических единиц напрямую связаны с действием механизмов оперативной и долгосрочной памяти и процессами программирования речевого высказывания, внося тем самым ограничения в объём лексики, представляемой для усвоения.

В этот период необходимо ввести и закрепить минимум общенаучной и специальной лексики, синтаксических структур, характерных для определённой специальности. Необходимо учитывать тот факт, что именно на начальной стадии изучения языка специальности учащиеся сталкиваются с большим количеством языковых, психологических и межкультурных трудностей, поэтому на начальной стадии обучения текстовой материал по языку специальности должен быть максимально доступен для понимания слушателей довузовского этапа обучения. Количество новых лексических единиц в уроке, включая терминологические, не должно превышать 1520. Следует помнить, что в полинациональных группах студентов обучается много слушателей, не владеющих ни одним из европейских языков, поэтому включенные в тексты термины интернационального характера (сuстема, структура, классификация, анализ, факт и др.), являются для них новыми и неизвестными.

Анализ «Требований по русскому языку как иностранному I сертификационный уровень. Профессиональный модуль» (гуманитарный (650слов); филологический (740 слов) профили) [6] позволил выявить универсальные конструкции (их в каждом из указанных минимумов до 50 \%), свойственные практически всем гуманитарным и филологическим наукам, и достаточно просто поддающимся объяснению с помощью толкования, синонимии и антонимии. Именно поэтому обучение языку специальности начинают с введения лексико-грамматических конструкций ЧТО? это ЧТО?; ЧТО? представляет собой ЧТО?; ЧТО является ЧЕМ? и конструкции ЧТО? играет 
важную роль в ЧЁМ?

История - это наука о появлении и развитии человеческого общества.

Человек существует на Земле примерно два миллиона лет. Человеческое общество развивается и изменяется. Процесс развития человеческого общества имеет свои законы, а история изучает и объясняет эти законы. История рассказывает нам, как жили люди много тысяч лет назад. Эта наука играет большую роль в изучении жизни общества и культуры народа. [7].

Литература - это вид искусства. Художественная литература входит в систему других видов искусства. Существуют различные виды искусства. Живопись - это изобразительное искусство. Театр, кино, телевидение представляют собой зрелищное искусство. [8].

Приведённые выше примеры из учебных пособий по научному стилю речи неслучайны, так как первыми специальными предметами, вводимыми, как правило, уже на 10-12 неделе обучения, являются «Литература» и «История России».

Однако, начиная с 3-4 урока указанных пособий, лексическое наполнение становится более специфичным, отвечая конкретным задачам той или иной специальности.

Проведём анализ пропедевтического курса на материале литературоведения и литературы для студентовфилологов довузовского этапа обучения.

В этом пособии можно выделить 3 основные темы: «Литература как искусство»; «Литературоведение как наука»; «Жизнь и творчество писателя». Каждая из этих тем содержит определённый набор лексики, синтаксических структур и текст, который призван выполнять познавательную, воспитательную, системно-языковую и коммуникативную функции.

Презентация темы «Литература как наука» совпадает по временным рамкам с окончанием изучения предложно-падежной системы, представленной в уровне A1 и частично в уровне А2.

Рекомендуется введение следующих глаголов действия таких, как значить, создавать, происходить, считать (в значении «думать»), использовать, существовать, появляться, определять, возникать и др.; отглагольных существительных: значение, создание, использование, развитие, изучение, появление, возникновение; прилагательных: общественный, культурный, духовный, материальный и др.
В теме «Литературоведение как наука» рассматриваются основные литературные понятия. Именно в этой части, как правило, вводится абсолютное большинство специализированной (тематической) лексики: жанры литературы (эпические, лирические, драматические), роды и виды литературы, литературные направления (классицизм, романтизм, сентиментализм, реализм, модернизм) и возникающие в процессе работы над текстами словообразовательные цепочки.

Углубленная работа над литературоведческими дефинициями не является задачей преподавателя-русиста. В то время как работа со словообразовательными цепочками является чрезвычайно важной для развития понимания словообразовательной системы русского языка.

Необходимо научить слушателя находить корень слова и на основе сопоставления с ранее изученной грамматикой определять морфологические признаки того или иного слова. Такое представление лексического материала помогает запоминанию большего количества лексических единиц языка и даёт инофонам языковую опору для развития навыков самостоятельной семантизации незнакомой лексики.

При работе над вышеуказанной темой преподаватель стремиться познакомить учащихся с синонимическими конструкциями: Что? входит в состав Чего? - Что? включает Что? - Что? cocmoum из Чего?; Что? влияет на Что?- Что? оказывает влияние на Что?; Кто? уделяет внимание Кому? Чему? - Кто? обращает внимание на кого? на что?; Интересоваться Чем?- Проявить интерес к Чему?

Являясь, с одной стороны, достаточно универсальными, данные конструкции, обслуживая специфическую лексику, наполняются таким лексическим содержанием, которое характерно для языка изучаемого предмета: Писатели-реалисты уделяли большое внимание исторической правде; писатели - модернисты проявляли интерес к внутреннему миру человека.

В процессе работы по теме «Жизнь и творчество писателя» появляется необходимость в представлении лексико-семантической группы глаголов со значением действия писателя: создавать, изображать, оnисывать, раскрывать, выражать, отражать. Сложность работы над этими глаголами состоит в том, что они связаны синонимическими отношениями. Нюансы их употребления лучше всего усваиваются при подаче в лексических словосочетаниях: создавать произведения лирического жанра; писатели-романтики изображали сильную, свободную личность; писатель выражает свое отношение к жизни; писатели - модернисты отразили эпоху, идеи, настроение обшества. 
В этом же разделе появляются соотносительные с глаголом существительные, обозначающие чувства и отношения: любовь, ненависть симпатия, интерес, требующие дательного падежа и предлога: любовь к природе, симпатия к герою, интерес к человеку и т.n.

Данные словосочетания входят в компонентную группу глаголов показывать и выражать.

При работе над темой «Жизнь и творчество писателя» лексический контент обогащается и расширяется как за счёт глагольных сочетаний, выражающих позитивное или негативное отношение автора к тому или иному явлению, так и за счёт лексических словосочетаний, характеризующих эпоху, в которой жил и работал писатель: nроисходить; выступать за (против) кого? чего?; осуждать кого? что?; оченить что?; сочувствовать кому? чем?; бороться за что? против кого? с кем?; защищать кого? что?; изменяться.

Как поэт Пушкин формировался в тот период, когда Россия переживала важное историческое событие - войну с Наполеоном (1812 год). Героическая борьба русского народа воспитала в нём чувство патриотизма. Свой долг, долг поэта и граждани́на, А.С. Пушкин видел в служе́нии России. Поэт выступал против крепостно́го пра́ва и угнете́ния народа. [9]

Указанная лексика представляет собой лексико-семантические группы, в которые входят слова со значениями возникновения, событийности, существования, изменения, результативности и т.п. В данном смысловом блоке присутствует лексика со значением времени и пространства и со значением процесса формирования личности: оказать влияние, сформироваться, измениться и $\partial p$.

Немаловажное значение, определяющее набор изучаемой лексики, играет типологический текст, содержащийся в уроке.

Под типом текста следует понимать «образец, модель однородной группы текстов, имеющих общие характерные для этой группы экстра- и транслингвистические признаки, обусловленные родом речемыслительной деятельности, сферой коммуникации и речевой ситуа- цией» [10].

Ряд учёных (Беспалько В.П., Татур Ю.Г., Смирнова и др.) [11] предлагают рассматривать типологический текст с лингвистической, психологической точки зрения, подчёркивая, что обучающий текст должен обеспечивать раскрытие учебной дисциплины, создавать условия для самостоятельной творческой работы студентов, формировать его профессиональный уровень. С другой стороны, текст должен быть доступным для успешного освоения учащимися, способствовать мотивации к обучению.

Несмотря на то, что в настоящее время всё больше учёных-лингвистов предлагают использовать в научном стиле речи аутентичные тексты, авторы статьи придерживаются той точки зрения, что для начального (довузовского) этапа обучения необходимо использовать адаптированные тексты, построенные с учётом представленной в притекстовых упражнениях лексики и лексико-грамматических конструкций, которые могут содержать как слова и словосочетания для перевода, так и для толкования с помощью синонимических и антонимических конструкций.

Для закрепления и контроля лексико-грамматического материала используется система послетекстовых упражнений, которые призваны активизировать изученную лексику путём включения упражнений репродуктивно-продуктивного и продуктивного характера, способствующих порождению монологического высказывания.

Таким образом, планируя и организуя работу над лексическим аспектом на уроках по языку специальности, авторы считают целесообразными следующие рекомендации:

- опора на частотную общеупотребительную, общенаучную, тематическую терминологическую лексику, соответствующую предметному содержанию урока и курса в целом с учётом её семасиологической и экстралингвистической значимости;

- соблюдение принципа минимизации лексики, концентричности ее презентации;

- использование типологических текстов, представляющих лексику в её функциональной роли.

\section{ЛИТЕРАТУРА}

1. Б.В. Беляев «0черки по психологии обучения иностранным языкам». М.: Просвещение, 1965,- С.227

2. Андрюшина Н.П. Козлова Т.В. Лексический минимум по русскому языку как иностранному. Элементарный уровень. Общее владение, - 5-е издание- , Спб.: «Златоуст». 2014, -80 c.

3. Андрюшина Н.П. Козлова Т.В. Лексический минимум по русскому языку как иностранному. Базовый уровень. Общее владение, -5-е издание-, Спб. :«Златоуст». 2013, -116 с. 
4. Андрюшина Н.П., Битехтина Г.А., Клобукова Л.П., Норейко Л.Н., Одинцова И.В. Лексический минимум по русскому языку как иностранному. Первый сертификационный уровень. Общее владение, -7-е издание-, Спб. :«Златоуст». 2014, -200 с.

5. Авторский коллектив: РУДН: 3.И. Есина, А.С. Иванова, Н.И. Соболева, Е.В. Сорокина, Г.А. Сучкова, Т.В. Шустикова. МГу: М.М. Нахабина, В.А. Степаненко. МАДИ: Г.В. Артемьева, В. Дубинская. СПбГТУ: И.И. Баранова, Г.И. Кутузова, В.В. Стародуб Образовательная программа по русскому языку как иностранному, Москва 2001, - С.134

6. Н.П. Андрюшина, Г.А. Битехтина, Т.Е. Владимирова, А.С. Иванова, Л.П. Клобукова, Л.В. Красильникова, М.М. Нахабина, Н.И. Соболева, В.В. Стародуб, В.А. Степаненко Требования к первому сертификационному уровню владения русским языком как иностранным. Общее владение. Профессиональный модуль, 3-е издание, Спб «Златоуст», 2015

7. Богатырёва И.В., Крылова Н.Ю., Рубцова Д.Н., Пособие по научному стилю речи для студентов-иностранцев гуманитарных специальностей «По страницам русской истории», 2011 г

8. Косарева Л.А., Оганезова А.Е. Профессия - филолог. Литература - М.: Изд-во РУДН, 2005. - С. 85

9. Н.В. Поморцева, Н.М. Румянцева, Л.Б. Тёрёчик, Д.Н. Рубцова, Алимова М.В. Русский калейдоскоп //- Москва: РУдН, 2020, - 140 с.

10. Соловьев В.А. «Типология текстов с коммуникативно-функциональной точки зрения», Москва 1984 г., -112 с.

11. Е.Г. Беспалько, Татур Ю.Г. Системно-методическое обеспечения учебно-воспитательного процесса подготовки специалистов, М.: Высшая школа, 1989, $141 \mathrm{c}$.

( Р Рубцова Дина Николаевна (dina.rubtsova@yandex.ru), Румянцева Наталия Михайловна (natrum1@yandex.ru).

Журнал «Современная наука: актуальные проблемы теории и практики»

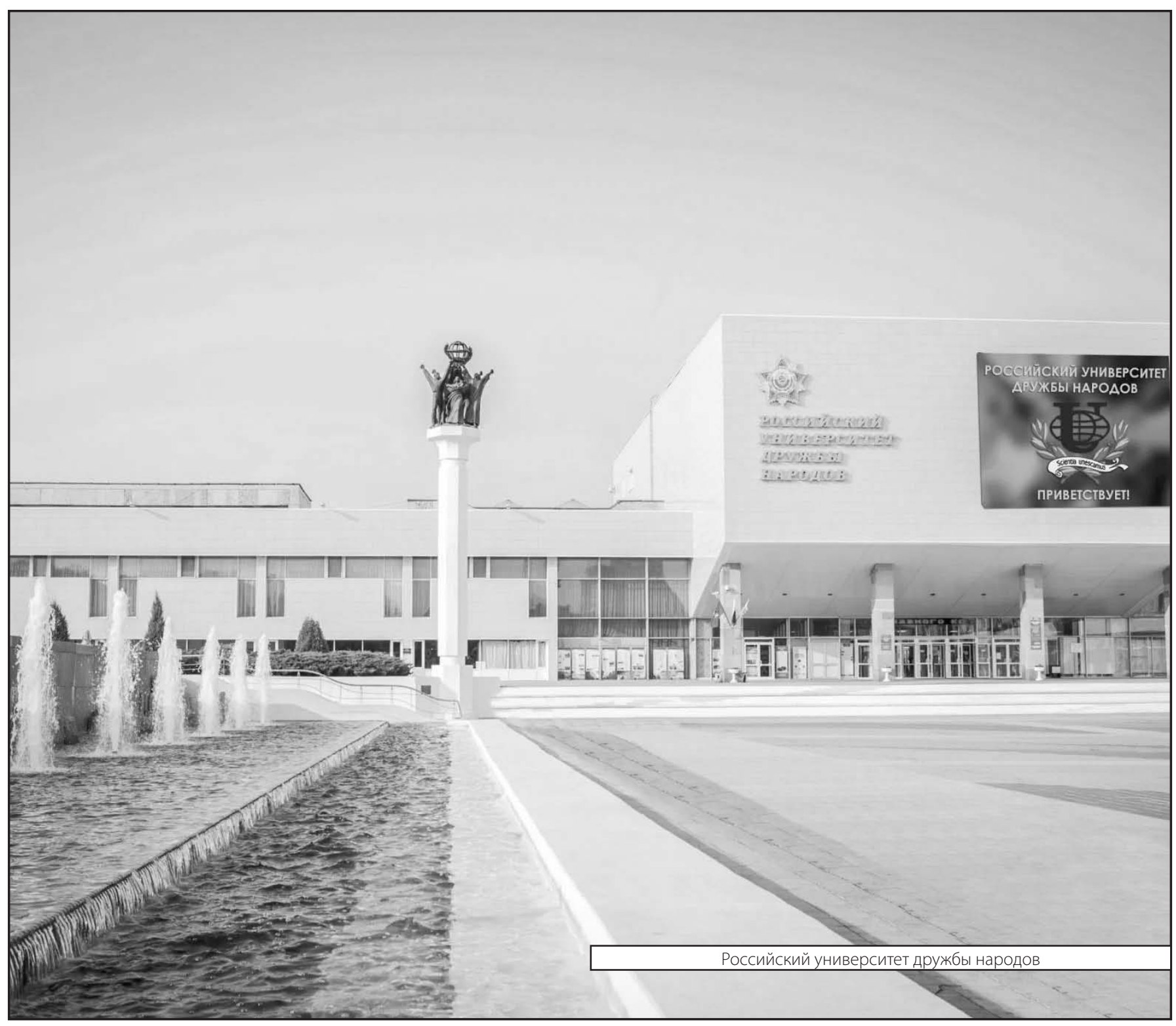

